\title{
ADORNO, SEMIFORMAÇÃO E EDUCAÇÃO
}

\author{
WOLFGANG LeO MaAR
}

\begin{abstract}
Que importa (...) a linha do horizonte? - O que eu vejo é o beco. (Manuel Bandeira, 1974, p. 228)

Quem quiser (...) a verdade da vida (...) tem que investigar sua configuração alienada. (Adorno, 1993, p. 7)

Abre-te, Sésamo, quero sair! (Stanislaw Lec, apud Adorno, 1999, p. 109)
\end{abstract}

\begin{abstract}
RESUMO: Semiformação (Halbbildung) é a determinação social da formação na sociedade contemporânea capitalista. Na perspectiva de Adorno, a sociedade deve ser apreendida em seu processo de reprodução material como reificação, mediação socialmente invertida. Cabe à teoria ir além do momento subjetivo da coisificação, ao decifrar as determinações objetivas da subjetividade. Não basta só revelar o sujeito por trás da reificação: ele é também socialmente determinado na adequação ao vigente, como sujeito que se sujeita e não experiencia as contradições sociais da produção efetiva da sociedade, ocultas ideologicamente na ordem social imposta pela indústria cultural. A educação não é idealista, para a emancipação, mas dialeticamente baseada na crítica à semiformação real e se orienta por possibilidades presentes, embora não concretizadas, na experiência das contradições da formação social efetiva.
\end{abstract}

Palavras-chave: Adorno. Formação (Bildung). Indústria cultural. Dialética materialista. Fetichismo.

\section{ADORNO, SEMI-FORMATION AND EDUCATION}

ABSTRACT: Semi-formation (Halbbildung) is the social determination of formation in the contemporary capitalist society. In Adorno's views, society, in its reproduction process, is to be apprehended as

Professor Adjunto do Departamento de Filosofia e Metodologia da Ciência da Universidade Federal de São Carlos (UfSCAR).E-mail:wmaar@power.ufscar.br 
reificated, as a socially inverted mediation. Theory has to go beyond the subjective moment of reification, and unravel the objective determinations of subjectivity. Showing the subject behind reification does not suffice since it is also socially determined in accordance with the existing society, as a subject that subjects itself and does not experience the contradictions of the effective production of society, ideologically concealed in the social order imposed by the culture industry. Education is not idealistically aimed at emancipation, but dialectically based on the critique of real semi-formation, and oriented by possibilities that are present, although not effective, in the experience of the contradictions of the effective social production.

Key words: Adorno. Formation (Bildung). Culture industry. Materialistic dialectics. Fetichism.

\section{A nova perspectiva da tendência à totalização social integradora}

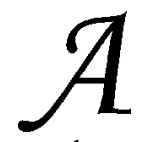
semiformação (Halbbildung) faz parte do âmbito da reprodução da vida sob o monopólio da "cultura de massas". A alteração de "cultura de massas" para indústria cultural explica-se justamente pela preocupação de Adorno e Horkheimer com o essencial em sua perspectiva: apreender a tendência à determinação total da vida em todas as suas dimensōes pela formação social capitalista, a subsunção real da sociedade ao capital (Marx, 1969, p. 49).

Cultura de "massas" parece indicar uma cultura solicitada pelas "massas", como se fossem "sujeito" pressuposto acriticamente, fora do alcance da totalização. Já o termo indústria cultural ressalta o "mecanismo" pelo qual a sociedade como um todo seria "construída" sob a égide do capital, reforçando o vigente (ver Maar, 2000). Os autores pensaram, nos termos da produção pela indústria capitalista, na construção da sociedade como sendo cópia feita na medida em que a sociedade é cultural, ordena e organiza o que seria natural. No ensaio Superstição de segunda mão, Adorno resume de modo exemplar: "(...) a indústria cultural como um todo (...) duplica na consciência dos homens o que existe." (Adorno, 1979, p. 175). Mas cumpre lembrar que "consciência" é "ser consciente", reflexão da determinação do ser que é a existência, e não uma "existência espiritual" contraposta dualisticamente à matéria "inconsciente".

O momento subjetivo deste social presente como cópia, como objetificação coisificada, seria decifrado na Dialética do esclarecimento como semiformação. A "cultura, tomada pelo lado de sua apreensão subjetiva, é a formação" (idem, ibid., p. 94). Nessa apreensão 
subjetiva do enfoque de "cultura", apreendida nos termos da indústria cultural que copia a sociedade em estrita continuidade de sua vigência, a "consciência" como "semiformação" corresponde à continuidade social, com uma cultura "afirmativa” (Marcuse, 1997, p. 89). As "massas" são semiformadas afirmativamente para confirmar a reprodução continuada do vigente como cópia pela indústria cultural.

Além do já exposto, é importante frisar a gênese conceitual de "indústria cultural" a partir de "cultura de massas" também para atentar à sociedade de massas. Ela caracteriza a novidade da formação social instalada em sua plenitude até meados do século XX no âmbito das relações sociais capitalistas, contexto em que a questão do sujeito exige perspectivas de apreensão próprias. Este era justamente o desafio a que se propôs o Instituto de Pesquisa Social, cujo leitmotiv eram as dificuldades em face da integração social de quem havia sido tomado como sujeito da revolução, a classe trabalhadora. A semiformação está em estreita relação seja com a razão instrumental (Horkheimer, 1976) seja com a função social da tecnologia (Marcuse, 1998, p. 71).

A sociedade de massas - talvez fosse melhor "sociedade massificada" - seria a forma social vigente assumida pela formação social em seu processo de reprodução na subsunção real e totalizante ao capital. Nessa subsunção se embaralha a contraditória estrutura da sociedade de classes, confundindo sua aparente nitidez objetiva e promovendo uma conciliação. "Toda sociedade ainda é de classes", diria Adorno no ensaio Sociedade; mas "subjetivamente encoberta, a diferença de classes cresce objetivamente" (Adorno, 1979, p. 15). A perspectiva dos interesses de classe ficaria prejudicada. Ante a ineficácia da ancoragem empírica dos interesses de classe, obnubilados na sociedade vigente, poder-se-ia enquadrá-los como construção ideal, elaborando culturalmente a situação de inserção objetiva no processo produtivo. Em George Lukács, a classe é a "classe da "consciência de classe", construção "adjudicada" nos interesses de classe ideais (Lukács, 1974, p. 24). Consciência de classe e cultura são vistos como emancipadores.

Deste prisma se distingue o foco da Teoria Crítica, em especial a perspectiva de Adorno (ver Maar, 2002), que não se baseia em uma idealização a ser realizada, mas se apóia na decifração crítica do presente já realizado e se realizando, no processo de reprodução apreendido como construção material-histórica determinada em sua 
forma social, num contexto de continuidade. A cultura tematizada no presente já não seria apreendida como ideal emancipadora, mas real conservadora ou "afirmativa". Como resultado, legitimaria a sociedade imperante, que reconstrói como "cópia" ordenada de modo estritamente afirmativo.

A teoria emancipadora da consciência de classe proletária, construção ideal-típica a orientar a intervenção social rumo à libertação do modo de reprodução vigente, seria substituída pela teoria crítica da semiformação da classe burguesa vigente, decifrada em sua forma social determinada, entre outras, como ordenamento de adequação, de sujeição aos termos existentes da reprodução social. A realidade aparente ("o todo é o falso" em sua determinação social), mas produzida: é por este prisma, em que se decifram seus momentos constituintes, que se estabelece o único acesso à essência (reflexão que distingue o "verdadeiro"). "Não é o bem, mas o mal, que é objeto da teoria. Ela já pressupõe a reprodução da vida nas formas determinadas em cada caso. Seu elemento é a liberdade, seu tema a opressão" (Adorno \& Horkheimer, 1985, p. 204).

\section{Semiformação e indústria cultural}

$\mathrm{Na}$ Dialética do esclarecimento estão as primeiras referências à semiformação, ou "semicultura" em seu sentido formativo. Quais são as condiçôes da reprodução da vida dos homens sob as relações de produção dominantes na formação social caracterizada como sociedade de massas? No segmento "A indústria cultural: o esclarecimento como logro das massas", a questão seria referida à semiformação como uma determinada forma social da subjetividade socialmente imposta por um determinado modo de produção em todos os planos da vida, seja na produção, seja fora dela. Nesta medida, por exemplo, o chamado "direito à preguiça" de Lafargue já atentaria à semiformação dos homens, voluntariamente mantidos dominados pela ordem do trabalho mesmo quando não trabalham. $\mathrm{Na}$ citação a seguir, embora a referência conceitual da semiformação, em seu nexo fundamental com a indústria cultural, esteja presente, o termo propriamente dito ainda não aparece.

(...) as pessoas devem [o verbo no original é sollen] se orientar por essa unidade que caracteriza a produção. A função que o esquematismo kantiano ainda atribuía ao sujeito (...) é tomada ao sujeito pela indústria. $\mathrm{O}$ esquema- 
tismo é o primeiro passo prestado por ela ao cliente. (...) Muito embora o planejamento do mecanismo pelos organizadores dos dados, isto é, pela indústria cultural, seja imposto a esta pelo peso da sociedade que apesar de toda racionalização permanece irracional, essa tendência fatal é transformada em sua passagem pelas agências do capital de modo a aparecer como o sábio desígnio dessas agências. Para o consumidor não há nada mais a classificar que não tenha sido antecipado no esquematismo da produção. (...) todos os detalhes, clichês prontos para serem empregados arbitrariamente aqui e ali e completamente definidos pela finalidade que lhes cabe no esquema. Confirmá-lo, compondo-o, eis aí sua razão de ser. O mundo inteiro é forçado a passar pelo filtro da indústria cultural. A velha experiência do espectador de cinema que percebe a rua como um prolongamento do filme que acabou de ver, porque este pretende reproduzir rigorosamente o mundo da percepção cotidiana, tornou-se a norma da produção. Quanto maior a perfeição com que suas técnicas duplicam os objetos empíricos, mais fácil se torna hoje obter a ilusão de que o mundo exterior é o prolongamento sem ruptura do mundo que se descobre no filme. (Idem, ibid., p. 117-118)

O mundo, que permanece irracional, seria reconstruído como racionalização, num esquematismo planejado que substitui o que seria a experiência do consumidor, antecipando-a sob os desígnios do capital, resultando na ilusão de que o mundo exterior seria o prolongamento da produção nos termos da indústria cultural. No mundo reconstruído o sujeito semiformado toma-se como sujeito do mundo que meramente reproduz. Para ele a construção parece "natural”, mas é uma "segunda" natureza. No verbete "Para uma crítica da filosofia da história”, a questão retorna: “(...) a dominação conseqüente da natureza se impõe de uma maneira cada vez mais decidida e passa a integrar toda a interioridade humana" (idem, ibid., p. 208).

\section{O termo semiformação surge na Dialética do esclarecimento} citado em "Elementos do anti-semitismo":

Para ele [o homem semiformado] todas as palavras se convertem num sistema alucinatório, na tentativa de tomar posse pelo espírito de tudo aquilo que sua experiência não alcança, de dar arbitrariamente um sentido ao mundo que torna o homem sem sentido, mas ao mesmo tempo se transformam também na tentativa de difamar o espírito e a experiência de que está excluído, e de imputar-lhes a culpa, que, na verdade, é da sociedade que o exclui do espírito e da experiência. Uma semicultura [ou semiformação] que por oposição à simples incultura [ou ausência de formação] hipostasia o saber limitado como verdade, não pode mais suportar a ruptura entre o interior e o exterior, o destino individual e a lei social, a manifestação e a essência. Essa dor encerra, é claro, um elemento de verdade em comparação com a simples 
aceitação da realidade dada (...). Contudo a semicultura, em seu modo, recorre estereotipadamente à fórmula que lhe convém melhor em cada caso, ora para justificar a desgraça, ora para profetizar a catástrofe disfarçada, às vezes, de regeneração. (...) Os sistemas obscuros realizam hoje o que o mito do diabo da religião oficial realizava na Idade Média: a atribuição arbitrária de um sentido à realidade exterior. (...) a real emancipação dos homens não ocorreu ao mesmo tempo que o esclarecimento do espírito (...) quanto mais a realidade social se afasta da consciência cultivada, tanto mais esta se via submetida a um processo de reificação. A cultura converteu-se totalmente numa mercadoria. O pensamento perde o fôlego e limita-se à apreensão do fatual isolado (...) o pensamento reduzido ao saber é neutralizado e mobilizado para a simples qualificação nos mercados de trabalho específicos e para aumentar o valor mercantil das pessoas. Assim naufraga a auto-reflexão do espírito que se opõe à paranóia. Finalmente, sob as condições do capitalismo tardio, a semicultura converteu-se no espírito objetivo. (Idem, ibid., p. 182-184)

Note-se aqui que na apreensão do espírito na formação social o ponto de partida é o próprio processo de reprodução presente, apreendido pelos sujeitos nele (semi)formados como resultado a ser beneficiado. Esta é uma perspectiva materialista contraposta ao idealismo, que consagra um espírito como uma realidade ideal a ser efetivada no presente.

Mas o processo de reprodução é um ponto de partida em que ocorre uma inversão. A indústria cultural, "círculo de manipulação e necessidades retroativas" (idem, ibid., p. 114), é “integração voluntária, pelo alto, de seus consumidores” (Adorno, 1973, p. 60), integração de quem "objetiva” por parte da objetivação. Como tal, "é decisiva para o espírito hoje predominante” (idem, ibid., p. 64), pois é fator que "duplica na consciência dos homens o que existe" (idem, 1979 , p. 175), formando a consciência ao confirmar o mundo na ordem estabelecida. Por isso, em Critica cultural e sociedade, de 1949, Adorno diria que a ideologia agora é "a própria sociedade" (idem, 1977 , p. 26) e falso não se refere ao ideológico, mas a que a "cópia" da sociedade se imponha como sendo a efetiva. O "todo" é o falso, em sua ordem determinada. O "espírito" assim construído volta-se contra o espírito - "a semiformação hipostasia o saber limitado como verdade" (Adorno \& Horkheimer, 1985, p 182), produzindo a "consciência" correspondente.

Não só se parte do presente a ser decifrado como mediação, como efeito, mas nesta construção se revela uma inversão, uma sujeição que é o sujeito (Maar, 2001), que também é socialmente determinado. 
A "finalidade que cabe" aos sujeitos é serem sujeitos da reprodução de um mundo em que sua condição é de sujeitos sujeitados. Os sujeitos produzem sua sujeição no tempo, como semiformação. $\mathrm{Na}$ "mentalidade do ticket", a "perda da experiência acaba por transformar os adeptos do ticket progressistas em inimigos da diferença". Por seu turno, "o conteúdo do ticket fascista é tão vazio que só pode ser mantido (...)" (Adorno, 1985, p. 193).

"O esquema da cultura de massas", capítulo da primeira versão da Dialética do esclarecimento posteriormente retirado, esclarece essa perspectiva:

Os homens dão seu assentimento à cultura de massas porque sabem que aqui aprenderão os hábitos ("mores") de que precisam na vida monopolizada como passaporte [aqui se formam os sujeitos sujeitados]. Este só é válido quando pago com sangue, com a total cessão da vida, com a obediência subalterna face à odiosa imposição. Por isto, e não pela estultificação das massas que os inimigos destas produzem e os amigos lamentam, a cultura de massas é tão irresistível. (Adorno, 1984, p. 331)

Os "homens" aderem pelos efeitos desta adesão: na sociedade que se reproduz destacam-se os que aderiram. O preço da adesão - a sujeição e a conseqüente regressão subjetiva à semiformação - revelase uma determinação social auto-imposta pelos homens. Também na Minima moralia Adorno trata do tema:

Os discursos habituais sobre a "mecanização" do homem são enganosos, porque o concebem como algo estático, que por "influências" de fora, através de uma adaptação a condições de produção a ele exteriores, sofre certas deformaçōes. Mas não existe substrato algum dessas "deformaçōes", nenhuma interioridade ôntica sobre a qual mecanismos atuariam de fora apenas: a deformação não é nenhuma doença do homem, e sim uma doença da sociedade (...). É quando o processo que se inicia com a transformação da força de trabalho em mercadoria permeia todos os homens - transformando em objetos e tornando a priori comensuráveis cada um de seus impulsos, como uma variante da relação de troca - que se torna possível à vida reproduzir-se segundo as relações de produção imperantes. (Adorno, 1993, p. 201)

Nesta perspectiva, os homens permanecem sujeitos da reprodução da vida, e por isso são responsabilizados. A efetiva subjetividade na e da sujeição - a sobrevivência do sujeito "exige frieza, o princípio básico da subjetividade burguesa” (idem, 1990, p. 356), calculada como tempo de trabalho abstrato no modo de produção imperante está na seqüência de "O esquema da cultura de massas": 
Mediante a regressão se ratifica a recusa da resistência. As massas tiram as conseqüências da completa impotência social frente ao monopólio, em que hoje em dia se traduz a progressão da miséria. Na adequação às forças produtivas técnicas, que o sistema lhes impóe como progresso, os homens se convertem em objetos que se deixam manipular sem resistir, e deste modo regridem para aquém do potencial das forças produtivas técnicas. Mas como, enquanto sujeitos, permanecem sendo eles próprios os limites da reificação, a cultura de massas precisa continuamente, em uma má infinitude, apossar-se de novo dos mesmos: o desesperançado esforço de sua repetição constitui o único vestígio da esperança de que a repetição é inútil, de que os homens [no sentido em que produzem sua própria conversão em objetos] afinal não podem ser apropriados. (Idem, 1984, p. 331)

A "vontade" seria apreendida também no contexto da sujeição na formação socialmente determinada. Em uma carta de 1935 a Walter Benjamin, Adorno insistira:

o fetichismo da mercadoria não é um fato da consciência mas é dialético, (...) produz consciência. Isto significa que a consciência não pode simplesmente descrevê-lo (...), mas responde ao mesmo em pé de igualdade, com vontade e temor. (Idem, 1980, p. 111; grifos meus)

Não basta apenas referir-se ao momento subjetivo ou social presente na sociedade objetivada; além disso, esse momento precisa ser decifrado em seus próprios momentos, também socialmente determinados. De um lado, os homens determinados como não podendo ser apropriados, na qualidade de sujeitos; do outro, os homens em sua determinação social de manipulados como objetos, pela constituição de novas necessidades que são retroativas, isto é, formadoras de subjetividade. Este esquema apareceria agora como reificação a ser decifrada (Abre-te, Sésamo, quero sair! - Stanislaw Lec, apud Adorno, 1999, p. 109), num uso específico do conceito por Adorno e que representa a chave para decifrar sua teoria da semiformação.

O nexo entre sujeição e sujeito constitui o que poderíamos chamar a contradição em processo a ser decifrada em sua dialética, parafraseando famosa passagem dos Grundrisse de Karl Marx:

O capital é ele próprio a contradição em processo (porque) impõe a redução do tempo de trabalho a um mínimo, enquanto por outro lado dispóe o tempo de trabalho como única medida e fonte de riqueza. (...) De um lado, portanto, convoca à vida todos os poderes da ciência e da natureza, bem como da combinação social e da comunicação social, para tornar a produção da ri- 
queza (relativamente) independente do tempo de trabalho aplicado. Por outro lado, quer medir pelo tempo de trabalho as enormes forças sociais assim geradas, para assim contê-las nos limites que se impóem para conservar como valor o valor já criado. As forças produtivas e as relações de produção ambas lados diferentes do desenvolvimento do indivíduo social - aparecem ao capital apenas como meios e são apenas meios para ele produzir a partir de sua base limitada. In fact, contudo, constituem as condições materiais para explodi-la [a base limitada do capital]. (Marx, s/d., p. 593-594)

A semiformação seria a forma social da subjetividade determinada nos termos do capital. É meio para o capital, e simultaneamente, como expressão de uma contradição, sujeito gerador e transformador do capital. Adorno, ao contrário do resignado pessimismo equivocadamente associado com sua obra, apresenta uma alternativa prática real para a tendência à totalização social dominante, ao revelar a construção objetiva da formação social presente. Assim, em oposição à fatal "gaiola de ferro" de Max Weber, o viés idealista-ético, que impõe ao indivíduo "uma ordem de coisas inalterável na qual deve viver” (Weber, 1967, p. 34), seria substituído pela perspectiva materialista-dialética de Adorno. Nesta, o que parece ética formal ou cálculo racional se decifra como semiformação pela indústria cultural, que obstrui numa forma social determinada a contradição material presente em sua determinação social.

\section{A Teoria da Semiformação e o fetichismo da mercadoria}

É preciso decifrar a cultura e a formação no presente em seus momentos constitutivos, pelos seus efeitos, e não interpretá-las à luz de uma explicação idealista, pressuposta nos termos da própria semiformação. Em sua Teoria da Semiformação, de 1959, Adorno explicita:

No clima da semiformação os momentos da formação que são reificados ao modo das mercadorias perduram à custa de seu conteúdo de verdade e de sua relação viva com sujeitos vivos. Isso corresponderia à sua definição. (Adorno, 1979, p. 103; grifos meus)

Nesta medida se introduz a questão da semiformação. Mas a função social objetiva, o tema central, só se explicita na medida em que se desenvolve a perspectiva da sua apreensão em uma dupla reflexão, conforme a apreensão adorniana do fetichismo. 
A semiformação "não pode ser explicada a partir de si mesma, porque constitui resultado de um processo de dominação sistemática por mecanismos das relaçóes político-econômicas dominantes" (Schmied-Kowarzik, 1983, p. 114). Não basta permanecer no "plano" da sujeição; é preciso avançar à própria produção desse "plano", conforme uma "teoria mais ampla". Cabe responder à pergunta: "Como os homens se sujeitam a si próprios, impondo a si o imperativo categórico: 'Sujeita-te àquilo que existe!?’" (Adorno, 1973 , p. 67). A sujeição efetivamente vale como determinação "objetiva" no "plano" do já "objetivado" pelo verdadeiro "sujeito", revelado "para além" da sociedade já constituída, como aquele "sujeito limite da reificação", porque ele "produz reificação" e "se subordina voluntariamente a ela".

Que a semiformação, apesar do esclarecimento da ilustração e da difusão de informações e mesmo por seu intermédio se tornou a forma dominante da consciência contemporânea - é justamente isto que exige uma teoria mais ampla. A idéia de cultura não deve ser sacrossanta para ela, conforme é hábito da própria semiformação. A formação cultural (Bildung) nada mais é do que a cultura pelo lado de sua apropriação subjetiva. A cultura, porém, tem um caráter duplo. Ele remete de volta à sociedade e mediatiza entre a mesma e a semiformação. (Adorno, 1979, p. 94)

Caberia decifrar as determinaçôes objetivas deste momento subjetivo, evitando deter-se satisfeito na revelação simples do social presente na objetivação. Esta dupla reflexão social constitui a profundidade necessária para apreender a dialética da produção e da transformação histórica, para além da mera interpretação da sociedade já instalada ("Os homens só interpretaram o mundo; é preciso transformá-lo!"). Nos Epilegômenos dialéticos postumamente publicados, Adorno denominaria esta dupla reflexão de "segundo giro copernicano" (zweite kopernikanische Wendung) (Adorno, 1969, p. 155).

Como indústria cultural, o que se instala como "cultural" remete à sociedade copiando a si própria, perenizando-a ao orientarse pela interpretação retroativa da sociedade já feita. Neste sentido, "cultura" é a sociedade como ideologia. Mas, ao ser sociedade neste sentido ideológico, de reconstrução integrada dela mesma, sem as arestas das contradiçóes que perfazem a dialética do social vivo - como dialética "congelada" - a cultura mediatiza entre a sociedade e a semiformação. As condições da produção material existentes impõem esta forma cultural-ideológica e são refletidas na semiformação. Esta 
é uma formação social determinada, sujeitada no curso da formação social destas formas determinadas de produção e de formação, a sociedade, cuja forma dominante de consciência será doravante a semiformação.

Nesta segunda reflexão, as determinações "objetivas" da subjetividade também aparecem como sendo formadas, decifrando-se assim como "autonomização" com relação ao processo de formação, que reflete sobre a sociedade mediante um "clima" - a forma social - que reproduz as condiçōes que instalam a semiformação, como "círculo de manipulação e necessidades retroativas". Adorno conduz a investigação histórico-social para além dos pressupostos do indivíduo e da sociedade vigentes, e desvendaria a sociedade como processo de autoformação.

A formação no presente pauta-se pela adequação na continuidade do existente; é semiformação. É formação determinada em sua forma pela própria formação social, pela determinação social (modo) da produção. A negação determinada é o que podemos fazer no plano do já dado em direção ao porvir. Para Adorno essa negação seria efetivamente posta como "única possibilidade" que ainda resta à formação; isto é, o que se mantém de movimento real para além das imposiçōes objetivas que se abatem sobre a formação e que pode ser circunscrito no âmbito do existente; o que seria o seu potencial dialético.

A semiformação é "o espírito tomado pelo caráter fetichista da mercadoria” (Adorno, 1979, p. 108).

Se os homens desenvolveram o espírito para se conservarem vivos, as formações espirituais, de outro modo sequer existentes, já não são meios de sobrevivência. A autonomização inexorável do espírito face à sociedade, a promessa da liberdade, é tão social quanto o é a unidade de ambos. (Idem, ibid., p. 121)

A reificação expressa na autonomização - a espiritualização do espírito - não deve ser "simplesmente negada", mas pensada como forma determinada entre outras. A existência é uma determinação, e o real não deve ser eliminado como absoluto, mas negado em sua determinação, num movimento de superação e conservação que é a negação determinada.

Quando aquela autonomização é simplesmente negada, o espírito é oprimido e constitui a ideologia do existente não menos do que quando usurpa ideologicamente o absoluto. O que pode sem mácula ser denominado de cultural, para além do fetichismo da cultura, é unicamente o que se realiza graças à integridade de sua própria configuração espiritual e atua de volta so- 
bre a sociedade apenas de modo mediatizado, por meio desta integridade, $\mathrm{e}$ não mediante a adequação imediata às suas imposiçóes. A força para tanto o espírito só a encontra no que alguma vez foi a formação cultural. Se o espírito só gera o socialmente justo quando não se dissolve na identidade indiferenciada com a sociedade, então está na hora do anacronismo: fixar-se na formação cultural quando a sociedade lhe subtraiu sua base. Mas ela não tem nenhuma outra chance de sobreviver senão a da auto-reflexão crítica sobre a semiformação em que necessariamente se converteu. (Idem, ibid., p. 121; grifos meus)

Pela via do fetichismo da mercadoria, o que é social aparece como se fosse objetividade natural. Mas, para além disso, o modo de produção impóe formas determinadas a este social objetivado, de maneira que, como "consciência" sujeitada, elas reproduzem a sujeição ao mesmo tempo em que geram experiências substitutivas pelas quais se simula a constituição de sujeitos livres. Por isso, a "fenomenologia da consciência burguesa, por si só, não basta para a elucidação da nova situação" (idem, ibid., p. 100); é preciso alcançar a base efetiva em que se sustenta o que é causa das contradições da consciência burguesa.

Adorno não se contenta em decifrar em sua objetividade o social que está subsumido no objeto aparentemente natural. Mas procura, além disso, decifrar o social em sua subjetividade, revelando o momento subjetivo deste sujeito social, as formas sociais determinadas do social - a consciência burguesa. Mostra assim a contradição e as possibilidades desse social. Eis a inflexão teórica fundamental. A formação regressiva da consciência burguesa dispõese no lugar da consciência de classe emancipada atribuída ao proletariado, tomando como ponto de partida o próprio processo real de reprodução material em sua base contraditória.

O problema do fetichismo não termina com a revelação do social na objetivação petrificada, mas conduz à necessidade de decifrar as determinações objetivas desse social (a base), pelo qual a própria produção, como subjetividade, seria determinada de modo que se preserve a continuidade do vigente, na medida em que lhe corresponderia uma determinada consciência. Haveria uma imposição social profunda no que chamamos a subjetividade decorrente do processo pelo qual os seres humanos produzem materialmente, também ela determinada. Ali se localiza o fundamento material efetivo da semiformação: "As condiçôes da própria produção material dificilmente toleram aquele tipo de experiência com que atinavam os conteúdos tradicionais da formação" (idem, ibid., p. 101; grifos meus). 


\section{Semiformação, educação e política}

Primordial na questão da semiformação é não perder de vista a constelação em que se dá seu foco. Para Adorno não basta examinar formação, semiformação ou cultura, tais como se verificam na sociedade vigente. É preciso investigá-las tendo como referência o contexto de produção $d a$ sociedade, como formação social autogerada pelos homens e aprendida em sua dialética histórica. Cultura e formação precisam ser examinadas fora do âmbito estritamente cultural ou pedagógico definidos na sociedade, para serem investigadas no plano da própria produção social da sociedade em sua forma determinada. A via régia de acesso ao essencial é o processo de sua reprodução vigente em seu aparecer real, presente.

Em Critica cultural e sociedade, Adorno destacara: hoje a sociedade ela própria é sua ideologia. Essa ideologia já não seria um conjunto ideal no plano das idéias, mas a própria ordem social. A semiformação vai muito além de uma "perturbação pedagógica" no interior de uma determinada situação social educacional. Refere-se a uma forma ordenada da sociedade contemporânea determinada conforme um certo modo de produção social dos homens, e somente neste âmbito pode ser adequadamente apreendida.

$\mathrm{Na}$ Introdução à sociologia, último curso oferecido por Adorno, as relaçóes entre sociologia e economia política exemplificam o nexo entre educação e política que se pretende expor aqui.

Minha tese é a seguinte: pela separação estrita entre sociologia e economia política (...) ambas as disciplinas passam ao largo do que seria fundamental. A sociologia se restringe a opiniōes e preferências, ou a relaçōes interpessoais, formas sociais, instituições, relações de dominação e conflitos. Abstrai do que seria propriamente a raison d'être de todos estes momentos e a medida pela qual tudo isto poderia ser mensurado; ou seja; se abstrai do processo da reprodução real da sociedade humana; se abstrai da constatação de que afinal todos estes gigantescos processos sociais conectados pela troca não podem ter sentido algum senão sobretudo o de garantir e manter em movimento a vida de todo o gênero humano, materialmente e em seu padrão cultural. (...) A sociologia abre mão da produção social e da reprodução da vida da sociedade como um todo, e se algo constitui uma relação social, então é precisamente essa totalidade. (Adorno, 1993a, p. 236-237)

Tudo se passa como se estivéssemos simultaneamente em dois "planos" de ordenamento social, que são momentos no movimento dialético da sociedade efetiva. O "plano" da produção social material 
efetiva, determinada, dos homens em sua interação entre si e com a natureza, conforme um determinado modo de produção socialmente determinado - que é o "plano" de ordenamento social da produção $d a$ sociedade, o "social”. E o "plano" da sociedade constituída por este determinado modo, cuja própria organização retrata aquela determinada maneira em que os homens produzem no primeiro plano, parecendo ser a sociedade em que produzimos - o "plano" de ordenamento social da produção na sociedade, o "cultural". A crítica nesse plano cultural precisa referir-se ao plano social. Estes são os termos que explicam o famoso título Crítica cultural e sociedade.

$\mathrm{Na}$ obra de Adorno, estes dois momentos dialéticos se apresentam em diversas ocasiōes, como no debate radiofônico "Educação para quê??" publicado em Educação e emancipação:

Penso sobretudo em dois problemas difíceis que é preciso levar em conta quando se trata de emancipação. Em primeiro lugar, a própria organização do mundo em que vivemos é a ideologia dominante - hoje muito pouco parecida com uma determinada visão de mundo ou teoria -, ou seja, a organização do mundo converteu-se a si mesma imediatamente em sua própria ideologia. Ela exerce uma pressão tão intensa sobre as pessoas que supera toda educação. (...) No referente ao segundo problema (...) emancipação significa o mesmo que conscientização, racionalidade (...) A educação seria impotente se ignorasse a adaptação e não preparasse os homens para se orientarem no mundo. Porém seria questionável igualmente se ficasse nisto, produzindo nada além de well adjusted people, em consequiência do que a situação existente se impõe no que tem de pior. (Adorno, 1995, p. 143)

O mundo dos homens é organizado de determinada maneira e é preciso decifrar as condições e os condicionantes que causam seu modo determinado de ser. A essência não está "atrás" da aparência, mas é a reflexão da aparência acerca de seu modo de aparecer de determinado modo, o arranjo determinado do mundo, a sociedade que é sua própria ideologia. A emancipação como "conscientização" é a reflexão racional pela qual o que parece ordem natural, "essencial" na sociedade cultural, decifra-se como ordem socialmente determinada em dadas condições da produção real efetiva $d a$ sociedade.

Ora, mesmo a produção integrada não deixa de ser uma produção. A produção $d a$ sociedade está sempre presente na sociedade, como contradição que resiste à sua conciliação. "Uma sociedade em que as contradiçôes fundamentais sobrevivem, também não pode ser integrada na consciência”, diria Adorno em um de seus últimos 
ensaios, Tempo livre (1969, p. 67). A contradição social é o "remédio" para a "doença da sociedade" que é a semiformação.

Aqui ele explicita o papel político da educação: a reflexão conscientizadora das contradições sociais destacadas na produção $d a$ sociedade limita a tendência à integração na sociedade. Em "Educação e emancipação" que encerra o livro de mesmo nome, o tema é decisivo:

À pergunta: "vivemos em uma época esclarecida?” Kant respondeu: "Não. Mas certamente em uma época de esclarecimento" (...) ele determinou a emancipação (...) não como uma categoria estática, mas dinâmica. (...) (Hoje) isto se tornou muito questionável, face à pressão inimaginável exercida sobre as pessoas, pela própria organização do mundo (e) (...) pelo controle planificado até mesmo de toda realidade interior pela indústria cultural. Se não quisermos aplicar o termo emancipação num sentido meramente retórico, (...) vazio como o discurso dos compromissos (...) é preciso começar a ver efetivamente as enormes dificuldades que se opõem à emancipação nesta organização do mundo (...). O motivo é a contradição social. (Adorno, 1995, p. 181)

A educação não é para a emancipação, compromisso com um fim ético idealizado no contexto social-cultural. A educação, para ser efetiva, é crítica da semiformação real, resistência na sociedade material presente aos limites que nesta se impóem à vida no "plano" de sua produção efetiva. A emancipação é elemento central da educação, mas, para ser real e efetiva, há que ser tematizada na heteronomia. A orientação normativa da educação não é imposta de fora, mas deve saltar de sua configuração histórica que, por suas contradições, "exige 'objetivamente' a partir de si própria sua transformação” (Adorno, 1999, p. 183). A contradição real objetiva aponta imanentemente para além de si, por meio da possibilidade de uma negação determinada - não abstrata - da ordem vigente. A "consciência" faz o papel de objetivação da contradição, por ser inversora na medida em que adequa.

Neste sentido, é preciso aplicar toda energia para que "a educação seja uma educação para a contradição e para a resistência" no existente, para se contradizer e resistir como modo de ir além do plano da reconstrução cultural e da vigência da semiformação, referindo-se ao plano da vida real efetiva. Por exemplo (...) "mostrando-se aos alunos as falsidades" presentes na vida da sociedade culturalmente construída e "despertando a consciência quanto a que os homens são enganados de modo permanente" (Adorno, 1995, p. 181-183). 
A chamada "mídia" em geral, mas em especial o cinema, constitui um contexto privilegiado para apreender este "esquema da cultura de massas" semiformador. Seja de modo direto, como no filme Mera coincidência, que revela a própria fábricação do logro, seja pela intervenção nos hábitos, como em $O$ expresso da meia-noite, que fabrica o ódio cultural de um modo ilegal. Seja pela sutil expressão da contradição, como Concorrência desleal.

Em sua última aula na Universidade de Frankfurt, Adorno retornaria ao tema da semiformação. $\mathrm{Na}$ ocasião aconteciam mecanismos de personalização pela indústria cultural, exemplificados no casamento da princesa da Holanda com um nobre alemão.

A tarefa mais importante (...) da pesquisa social empírica atual seria investigar em que medida afinal os homens são e pensam tal como são feitos pelos mecanismos (da indústria cultural). Pesquisas do Instituto indicam (...) que ocorre uma duplicidade peculiar, isto é, de um lado as pessoas são obedientes aos mecanismos de personalização da indústria cultural (...), mas, simultaneamente, quando se vai além da superfície (...) todos praticamente são cientes de que (...) [em sua vida real] a princesa afinal não tem importância. Se realmente as pessoas são cativadas, mas ao mesmo tempo não são cativadas, se aqui ocorre uma consciência duplicada e contraditória em si mesma, então neste ponto o esclarecimento poderia se ater ao fenômeno da personalização e poderia ter êxito em esclarecer as pessoas que este fenômeno é apenas parte de um contexto mais amplo [a formação socialmente determinada da sociedade capitalista]. (Adorno, 1993a, p. 256)

Recebido e aprovado em maio de 2003.

\section{Referências bibliográficas}

ADORNO, T.W. Stichworte. Kritische Modelle 2. Frankfurt am Main: Suhrkamp, 1969.

ADORNO, T.W. Ohne Leitbild. Frankfurt am Main: Suhrkamp, 1973.

ADORNO, T.W. Prismen: Kulturkritik und Gesellschaft. Frankfurt am Main: Suhrkamp, 1977.

ADORNO, T.W. Soziologische Schriften. Frankfurt am Main: Suhrkamp, 1979.

ADORNO, T.W. et al. Aesthetics and politics. New York: Verso, 1980. 
ADORNO, T.W. Gesammelte Schriften. Frankfurt am Main: Suhrkamp, 1984. v. 3.

ADORNO, T.W. Negative Dialektik. Frankfurt am Main: Suhrkamp, 1990.

ADORNO, T.W. Minima moralia. São Paulo: Ática, 1993.

ADORNO, T.W. Einleitung in die Soziologie. Frankfurt am Main: Suhrkamp, 1993a.

ADORNO, T.W. Educação e emancipação. São Paulo: Paz \& Terra, 1995.

ADORNO, T.W. Textos escolhidos. São Paulo: Nova Cultural, 1999.

ADORNO, T.W.; HORKHEIMER, M. Dialética do esclarecimento: fragmentos filosóficos. Rio de Janeiro: Zahar, 1985.

BANDEIRA, M. Poesia completa e prosa. Rio de Janeiro: Aguilar, 1974. HORKHEIMER, M. Eclipse da razão. Rio de Janeiro: Labor, 1976.

LUKÁCS, G. Werke - 2. Frankfurt am Main: Luchterhand, 1974.

MAAR, W.L. A produção da "sociedade" pela indústria cultural. Revista Olhar, São Carlos, vol. 3, p. 84-107, 2000.

MAAR, W.L. Da subjetividade deformada à semiformação como sujeito. Psicologia e Sociedade, Belo Horizonte, vol. 13, n. 2, p. 92-141, 2001.

MAAR, W.L. A perspectiva dialética em Adorno e a controvérsia com Habermas. Transformação, Assis, vol. 25, p. 87-105, 2002.

MARCUSE, H. Cultura e sociedade. São Paulo: Paz \& Terra, 1997. v.1. MARCUSE, H. Tecnologia, guerra e fascismo. São Paulo: edUnesp, 1998. MARX, K. Grundrisse der Kritik der politischen Okonomie. Frankfurt am Main: EVA, 1967.

MARX, K. Resultate des unmittelbaren Produktionsprozesses. Frankfurt am Main: Verlag neue Kritik, 1969.

SCHMIED-KOWARZIK, W. Pedagogia dialética. São Paulo: Brasiliense, 1983.

WEBER, M. A ética protestante e o espírito do capitalismo. São Paulo: Pioneira, 1967. 